ÉTUDES ON THEORETICAL PHYSICS 
This page intentionally left blank 


\section{ÉTUDES ON THEORETICAL PHYSICS}

Collection of Works Dedicated to 65th Anniversary of the Department of Theoretical Physics of Belarusian State University

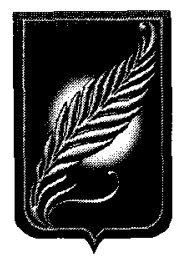

Editors

L M Barkovsky I D Feranchuk

Belarusian State University, Belarus

\section{Yakov M Shnir}

University of Oldenburg, Germany 


\section{Published by}

World Scientific Publishing Co. Pte. Ltd.

5 Toh Tuck Link, Singapore 596224

USA office: 27 Warren Street, Suite 401-402, Hackensack, NJ 07601

UK office: 57 Shelton Street, Covent Garden, London WC2H 9HE

\section{British Library Cataloguing-in-Publication Data}

A catalogue record for this book is available from the British Library.

\section{ETUDES ON THEORETICAL PHYSICS \\ Collection of Works Dedicated to 65th Anniversary of the Department of Theoretical Physics of Belarusian State University}

Copyright $\odot 2004$ by World Scientific Publishing Co. Pte. Ltd.

All rights reserved. This book, or parts thereof, may not be reproduced in any form or by any means, electronic or mechanical, including photocopying, recording or any information storage and retrieval system now known or to be invented, without written permission from the Publisher.

For photocopying of material in this volume, please pay a copying fee through the Copyright Clearance Center, Inc., 222 Rosewood Drive, Danvers, MA 01923, USA. In this case permission to photocopy is not required from the publisher.

ISBN $981-256-081-5$

Printed in Singapore. 


\section{FOREWORD}

This special volume devoted to the 65th anniversary of the Department of Theoretical Physics of the Belarusian State University presents the papers written by its leading scientists, researchers of the department as well as its graduates. The department was established in 1938 and its first head was Professor F.I. Fedorov who in fact became the founder of the School of Theoretical Physics in Belarus. His fundamental works on crystallooptics and acoustics, field theory and mathematical physics have received worldwide recognition. He also established high standards for teaching theoretical physics as the basis of physics education at the Belarusian state University - one of the universities in the former USSR. To do justice to F.I. Fedorov's contribution to the various fields of theoretical physics, one of the papers is devoted to his life and scientific career.

All other heads of the department followed the best traditions established by F.I. Fedorov and at the same time introduced their individual priorities in the researching and educational directions. In 1962 Professor A.E. Levashev headed the department during this period. The investigations in the field of gravitation theory were developed more actively. A number of important results in the quantum theory of condensed matter were obtained by scientists and researchers of the department when Professor L.I. Komarov was appointed its head in 1973. Professor G.V. Shishkin (head from 1982) made a considerable contribution to the development of the studies connected with the analysis of the Dirac equation in the general relativity. Professor L.M. Barkovsky headed the department in 1983 and, at the present moment, fundamental and applied problems of the electromagnetic and acoustic studies on the wave interaction with complex media are actively carried out under his supervision.

The papers in this jubilee edition cover a wide variety of research topics of modern theoretical physics. They have been researched for many years by the leading professors of the department and well-known scientists who graduated from it and are now working in research centers all 
over the world. Each contribution to this volume represents a brief review of the methods and techniques, numerical simulations and results in the corresponding fields of theoretical physics. We hope that this collection of papers will be of interest to scientists, researchers, post-graduates and students because the discussion of the qualitative and physical peculiarities of different problems was the focus of each author.

On behalf of all the authors of this edition, we would like to express sincere gratitude to Le Van Hoang, Yuri Zeldin and Mikhail Shurim who had graduated from the Department of Theoretical Physics but had remained faithful to their "alma mater" by supporting this project.

\section{Editors}

L. M. Barkovsky

I. D. Feranchuk

Ya M. Shnir

Minsk 20.6.2004 


\section{CONTENTS}

Foreword $\quad$ V

F.I. Fedorov's Contribution to the Creation and Development of Theoretical Physics in Belarus

T.A. Alexeeva, L.M. Barkovsky and A.A. Bogush

\section{Part I: Particles and Fields}

The Improved Deuteron Model with the Hyperbolic Relative Space

V.V. Kudryashov and L.M. Tomilchik

Non-Singular Cosmology and Gauge Theories of Gravitation

A. V. Minkevich

The Electrodynamics of Media Under Time-Reversal-Violation Condition (CP-Violation) and Possibility of T-Odd (CP-Odd) Interaction Testing Beyond the Standard Model

V.G. Baryshevsky

On One-Electron Atom in the Neighborhood of Black Holes

A.K. Gorbatsievich

Particle Physics and Quantum Chaos

V.I. Kuvshinov and A.V. Kuzmin

Polarization Symmetry of an Electromagnetic Field

V.I. Strazhev and P.L. Shckol'nicov

Multimonopoles and Closed Vortices in $S U(2)$ Yang-Mills-Higgs Theory

Y. Shnir 


\section{Part II: Mathematical Methods in Theoretical Physics}

Fedorov's Covariant Approach to Particle Physics and Vector Parametrization of Quantum Groups

A.A. Bogush

Characterizing and Designing Localized Electromagnetic Fields G.N. Borzdov

Operator Method for Nonperturbative Description of Quantum Systems

I. Feranchuk and A. Ivanov

Around Observables and Radiative Corrections

I. Akushevich, A. Ilyichev and N. Shumeiko

Processes of Lepton and Boson Birth in Linear Photon Collider

Tatiana V. Shishkina

Algebraic Method with the Use of Many-Particle Coulomb Green Function for Atomic Calculations

Le Van Hoang

Three-Dimensional Solitary Waves and Vortices in a Discrete Nonlinear Schrödinger Lattice

P.G. Kevrekidis, B.A. Malomed, D.J. Frantzeskakis and

R. Ċarretero-González

Ultrawide Spectral Broadening and Pulse Compression by High-Order Stimulated Raman Scattering V.P. Kalosha and J. Herrmann

\section{Part III: Condensed Matter and Complex Systems}

The Development of New Operator Methods for Describing Body and Surface Electromagnetic Waves in Complex Media

L.M. Barkovsky, G.N. Borzdov, A.N. Furs, A.V. Novitsky and V.M. Galynsky

Optical Waves in One-Dimensional Fractal Inhomogenous Media S.V. Zhukovsky, A.V. Lavrinenko and S.V. Gaponenko

Propagation of Light in Periodic Layered Structures and Waveguides Based on Photonic Crystals

D.N. Chigrin, A.V. Lavrinenko, D.N. Shyroky and V. V. Zhilko 
Radiation Forces in Classical and Quantum Physics

S.T. Zavtrak

Master Equation for Structured Reservoirs

353

D.S. Mogilevtsev and S. Ya. Kilin

Parametric X-Radiation: From the Theoretical Prediction to the First Observation and Applications

V. Baryshevsky and I. Feranchuk 